ISSN 0103-9954

\title{
CARACTERÍSTICAS DE COMPÓSITOS LAMINADOS MANUFATURADOS COM POLIETILENO DE ALTA DENSIDADE (PEAD) E DIFERENTES PROPORÇÕES DE CASCA DE ARROZ E PARTÍCULAS DE MADEIRA
}

\author{
CHARACTERISTICS OF LAMINATED COMPOSITES MANUFACTURED WITH HIGH DENSITY \\ POLYETHYLENE (HDPE) AND DIFFERENT PROPORTIONS OF RICE HUSKS AND WOOD \\ PARTICLES
}

\author{
Dalva Teresinha Pauleski $^{1}$ Clovis Roberto Haselein ${ }^{2}$ Elio José Santini ${ }^{3} \quad$ Eduardo Rizzatti $^{4}$ \\ RESUMO
}

Este trabalho teve como objetivo avaliar a viabilidade da utilização de casca de arroz e partículas de madeira para a manufatura de compósitos, tendo como agente ligante o polietileno de alta densidade (PEAD). Os compósitos foram produzidos com casca de arroz e partículas de madeira de Eucalyptus grandis, puras ou misturadas, sendo que cada tipo participou com 0, 25, 50, 75 e 100\% em proporção de peso seco. O PEAD foi usado como matriz na confecção destes, sendo testadas três proporções: 60,75 e $90 \%$. Os compósitos foram manufaturados de forma similar à fabricação de chapas aglomeradas com as dimensões de $0,5 \times 5 \times 25 \mathrm{~cm}$ formados em camadas em um molde de aço, e foram avaliadas as propriedades de flexão estática, ligação interna, absorção d'água e inchamento em espessura após 24 horas e após 15 ciclos de imersão. Os valores das propriedades de flexão estática foram influenciados pela massa específica do compósito. No caso da ligação interna, os valores ficaram dentro dos padrões estabelecidos pelas normas de comercialização para aglomerados convencionais, sendo o PEAD o parâmetro de maior correlação com essa propriedade. A casca de arroz provocou menor inchamento em espessura e, independente do tipo de matériaprima utilizada, os valores diminuíram à medida que a proporção de PEAD foi aumentada. Combinações com maior porcentagem de PEAD apresentaram valores mínimos ou, em alguns casos, nulos de absorção d'água. Para a absorção d'água e inchamento em espessura após 15 ciclos, o comportamento dos resultados foi semelhante aos dos testes de inchamento em espessura após 24 horas e absorção d'água após 24 horas. Os resultados permitem concluir que os compósitos produzidos com PEAD, casca de arroz e partículas de madeira puras ou misturadas apresentaram boa qualidade quando comparados aos aglomerados convencionais, evidenciando a viabilidade de uso desses materiais na confecção desse tipo de painel.

Palavras-chave: PEAD; partículas de madeira; casca de arroz; compósitos.

\section{ABSTRACT}

The objective of this work was to analyse the feasibility of the utilization of rice husks and wood particles in the manufacture of wood plastic composites, in a way similar to particleboard fabrication. The composites were made with rice husks and Eucalyptus grandis wood particles, pure or mixed, in proportions of $0,25,50,75$ and $100 \%$ of ovendry weight. High density polyethylene (HDPE) was used as matrix in the manufacture in three proportions: 60, 75, and 90\%. Bending properties, internal bond, water absorption and thickness swelling after 24 hours of water soaking and after 15 soaking cycles were evaluated. The values of bending properties were influenced by the density of the composite. In the case of internal bond, the values were within the limits established by commercial particleboard standards, being the HDPE proportion the parameter of higher correlation with this property. Rice husk caused lower thickness swelling and, independently of the type of raw material utilised, the values decreased with the increase of HDPE. Combinations with larger percentages of HDPE presented minimal values or, in some cases, null of water

1. Engenheira Florestal, MSc., Doutoranda pelo Programa de Pós-Graduação em Engenharia Florestal, Centro de Ciências Rurais, Universidade Federal de Santa Maria, Campus Universitário, CEP 97105-900, Santa Maria (RS). dpauleski@yahoo.com.br

2. Engenheiro Florestal, PhD., Professor do Departamento de Ciências Florestais, Centro de Ciências Rurais, Universidade Federal de Santa Maria, Campus Universitário, CEP 97105-900, Santa Maria (RS), haseleic@ccr.ufsm.br

3. Engenheiro Florestal, Dr., Professor do Departamento de Ciências Florestais, Centro de Ciências Rurais, Universidade Federal de Santa Maria, Campus Universitário, CEP 97105-900, Santa Maria (RS). Pesquisador do CNPq. santinie@ccr.ufsm.br

4. Engenheiro Civil, Dr., Professor do Departamento Estruturas e Construção Civil, Centro de Tecnologia, Universidade Federal de Santa Maria, Campus Universitário, CEP 97105-900, Santa Maria (RS).

Recebido para publicação em 15/09/2006 e aceito em 4/04/2007. 
absorption. For the water absorption and thickness swelling after 15 cycles the behavior was similar to that of the 24 hour period. Results allowed concluding that the composites made with HDPE, rice husks and wood particles pure or mixed present good quality, evidencing the adequacy of these raw material and process in manufacturing this type of panel.

Keywoods: HDPE; wood particles; rice husks; composites.

\section{INTRODUÇÃO}

A busca de tecnologias consideradas ecologicamente corretas tem se tornado uma grande preocupação nestes últimos anos. O novo paradigma do desenvolvimento econômico está voltado para propiciar a melhoria de vida das futuras gerações, incorporando na sua concepção modos de produção menos poluentes e impactantes. A grande quantidade de materiais de difícil degradação tem provocado sérios problemas ambientais, econômicos, sociais e legais.

Para Moraes et al. (1994), o agravamento da questão dos resíduos está diretamente relacionado ao aumento do consumo e a criação de materiais artificiais. O primeiro fator está associado ao crescimento populacional e ao aumento da geração de lixo per capita. O segundo fator está relacionado à criação de novos materiais com estruturas complexas, normalmente não-biodegradáveis ou de difícil degradação que apresentam um alto potencial de agressão ao homem e ao meio ambiente.

Com o aumento da demanda mundial por alimentos, tem-se buscado o aumento da produtividade e das áreas cultivadas. Porém, o volume colhido passa por vários processos de beneficiamento. Durante esses processos, grande parte do produto é descartado como resíduo, o qual, muitas vezes, não tem utilização adequada. Os resíduos estão se tornando um problema ambiental cada vez mais sério, uma vez que são produzidos em grandes quantidades e normalmente são de difícil decomposição.

O arroz (Oryza sativa), que é cultivado há mais de 6 mil anos, ajudou a fundar cidades e civilizações que precisavam se fixar na margem de rios para cultivá-lo. Porém, a partir do início do capitalismo, tornou-se importante fonte de lucro, tendo sua produção aumentada significativamente. A produção de resíduos, neste caso, fica por conta de sua casca, que, sendo composta basicamente de sílica e lignina, torna-se de difícil decomposição. Kaefer (2002) relata que o Brasil produz cerca de 12 milhões de toneladas de arroz/ano. A casca corresponde a $20 \%$ do peso do arroz, 2,4 milhões de toneladas que são rejeitadas todo ano, criando um grave problema ambiental e de saúde sobretudo nas regiões onde o cultivo do arroz se faz em larga escala.

Por outro lado, o mercado de embalagens, no ano de 2001, movimentou 5,75 milhões de toneladas (Datamark, 2002). Grande parte são embalagens plásticas que, após absorvidas pelo mercado consumidor, são descartadas como resíduo pós-consumo e, por não serem materiais biodegradáveis, tornam-se um sério problema ambiental. Esse material descartado poderia ser destinado para a confecção de novos materiais, como a produção de compósitos.

Em termos de uso final para o polietileno de alta densidade (PEAD), as embalagens representam $75 \%$ do mercado mundial. Do material plástico descartado após o seu uso, as embalagens são as que mais preocupam, pois, a cada ano, o volume desse resíduo aumenta, chegando a valores assustadores. A necessidade de encontrar uma utilização para esse material é de importância primordial para a conservação do meio ambiente, dado que sua decomposição leva centenas de anos (BNDES, 2000).

Atualmente, produtos feitos de materiais reciclados oferecem resistência, durabilidade e rentabilidade equivalente àqueles feitos de materiais virgens. O painel ecológico feito de madeira e material reciclado é uma das mais efetivas respostas para a demanda crescente de materiais.

Por exemplo, as fibras podem servir de reforço para compósitos. O reforço contribui para a resistência mecânica do material, enquanto que a matriz une as fibras, conservando a sua disposição geométrica, bem como as protegendo do ambiente exterior.

Dessa forma, a fabricação de painéis utilizando resíduo torna-se importante, pois, além de diminuir a necessidade de remoção, agrega valor aos produtos sem agredir o meio ambiente. Para que isso seja possível, deve-se estudar e testar novas opções que possam substituir, sem perda de qualidade do produto final, os materiais que, com o uso não-planejado, tendem à escassez num futuro próximo.

A utilização da casca de arroz e plástico na confecção de painéis surge como uma forma de 
solucionar o problema do acúmulo de resíduos e uma opção para a possível escassez de madeira, pois, além de eliminar sua propriedade de agente impactante e poluente, transforma um produto que antes era resíduo em matéria-prima para a indústria.

O presente trabalho teve por objetivo geral avaliar a viabilidade de utilização de casca de arroz e partículas de madeira puras ou misturadas para a manufatura de painéis, tendo como agente ligante o polietileno de alta densidade.

\section{REVISÃO BIBLIOGRÁFICA}

Compósitos termoplásticos são produtos obtidos partindo de uma matriz, contínua ou descontínua, de resina termoplástica reforçada com partículas de madeira ou fibras lignocelulósicas. Os produtos assim obtidos associam as melhores qualidades de cada constituinte e se caracterizam por apresentar propriedades peculiares, como baixa massa específica, grande estabilidade dimensional e grande resistência à corrosão, 0 que os distinguem de outros materiais (Maciel, 2001).

Existe uma grande variedade de materiais que podem ser combinados para a produção de compósitos (combinação de dois ou mais materiais unidos por algum tipo de betume ou matriz). Dentre eles, podem-se citar fibras virgens ou recicladas, resíduos agrícolas (bagaço de cana, palha de arroz e de trigo, bambu, algodão etc.) e polímeros sintéticos, como polipropileno e polietileno.

A potencialidade produtiva de fibras orgânicas, no Brasil, é muito grande, existindo por volta de vinte tipos úteis à construção civil. Os resíduos gerados pela agroindústria da fibra vegetal podem constituir, por seu turno, importante fonte de matéria-prima para produção de componentes construtivos, dependendo das quantidades disponíveis e da dispersão geográfica (John, 1996).

A cultura do arroz no Rio Grande do Sul tem importante papel na economia regional. É a principal atividade econômica em inúmeros municípios do Estado, notadamente na metade sul. Estudo realizado pelo IRGA (1996), visando a fornecer subsídios a investimentos pelo Programa de Fomento e Reconversão Produtiva da Metade Sul (RECONVERSUL), em 18 municípios da região sul do Estado, constatou que o arroz ocupava 49,8\% da área plantada das principais culturas temporárias naquela região. Em termos de valor da produção, o arroz detinha 78,1\%.

A mesma fonte cita que o Rio Grande do Sul tem ocupado lugar de destaque na produção de arroz no contexto nacional. Em 1980, a produção gaúcha correspondia a 23,4\% da produção nacional, alcançando patamares superiores a $40 \%$ a partir de 1990. A produção gaúcha de arroz cresceu de 874.185 toneladas em 1960 para 5.008.567 toneladas na última safra (base casca), um incremento de $473 \%$ (11,53\% ao ano). Na safra 99/00, o Rio Grande do Sul cultivou 25,6\% da área plantada com arroz no Brasil e respondeu por $44,5 \%$ da produção nacional, produzindo cerca de 5 milhões de toneladas anuais de arroz, com a sobra de 1 milhão de toneladas de casca. Apenas como comparação, uma fábrica de aglomerados típica utiliza em torno de 150 mil ton/ano de madeira, o que poderia ser substituído pela casca de arroz.

Segundo Riceboard (2001), o desenvolvimento da tecnologia para manufatura de painéis utilizando casca de arroz surgiu como uma das melhores soluções para os problemas dos resíduos da agricultura (casca de arroz) e, ao mesmo tempo, da preservação das florestas. Esses painéis podem substituir os painéis de partículas de madeira em diversos tipos de uso. Hancock \& Chandramouli (1974) disseram que as propriedades dos painéis produzidos com casca de arroz são similares às dos painéis com partículas de madeira. Quanto à resistência mecânica, painéis compostos com casca de arroz apresentaram maior resistência em relação a compostos com serragem (Casalina, 1972).

Vasishth (1971) demonstrou que painéis com casca de arroz podiam ser produzidos utilizando fenolformaldeído como adesivo, obtendo resultados satisfatórios. Chen (1979), em seus estudos, confeccionou painéis de partículas utilizando casca de arroz com fenol-formaldeído e obteve painéis de boas propriedades com relação à absorção de água, e à baixa expansão. Para o autor, as propriedades mecânicas dos painéis poderiam ser melhoradas com o aumento da densidade e do teor de adesivo.

Uma das características mais notáveis dos painéis de casca de arroz é a durabilidade; por ser material não-lenhoso, é imune ao ataque de brocas de madeira. Pela sua característica favorável em relação à absorção d’água e boa resistência, esses painéis podem ser usados na construção civil. Bulakul (1970) concluiu que o 
painel produzido com $50 \mathrm{~mm}$ de espessura apresentou resistência satisfatória, bom isolamento térmico e sonoro, além de alta resistência ao fogo. E, ainda, demonstrou possuir excelentes propriedades mecânicas, tais como: forte ligação interna, elasticidade, estabilidade dimensional, capacidade de suportar pregos e parafusos, resistência à abrasão, superfície dura, etc.

Por outro lado, a indústria de embalagens plásticas situou-se entre as de maior crescimento no Brasil nos últimos anos, segundo a Associação Brasileira de Embalagens Flexíveis. Os plásticos são divididos em duas categorias importantes: termofixos e termoplásticos (Compam, 2001). O consumo anual per capita de plástico no Brasil gira em torno de $10 \mathrm{~kg}$, sendo relativamente baixo, comparado com o índice de $72 \mathrm{~kg}$, verificado nos EUA, e de 53 kg, no Japão (Cepis, 2001).

Na produção de alguns compósitos que utilizam como matéria-prima principal o plástico/madeira, em razão de sua maior disponibilidade e adequação aos sistemas de produção, é necessária a fusão do material plástico, como o polietileno de alta e baixa densidade e o polipropileno em mistura com farinha de madeira e fibras de madeira (English et al., 1996).

Segundo Montenegro et al. (2002), o polietileno de alta densidade (PEAD) é um termoplástico de alta resistência a produtos químicos e solventes e uma baixa permeabilidade a gases e vapores. Sendo introduzido comercialmente na década de 50, o PEAD, atualmente, é o quarto termoplástico mais vendido no mundo, sendo também a segunda resina mais reciclada no mundo.

Em termos de reciclagem, o PEAD ocupa posição relevante em conseqüência da sua alta aplicabilidade nas embalagens. Os grandes produtores de resina virgem estão saindo do negócio, diante da sua baixa atratividade econômica. Cabe destacar ainda que é mínima a influência da reciclagem do PEAD em relação ao consumo total dessa resina. O PEAD reciclado representou apenas $4 \%$ do consumo de PEAD na América do Norte em 1994. As embalagens representam um total de 50\% do consumo de PEAD no Brasil, menor, portanto, do que a média verificada em termos mundiais (75\%).

\section{MATERIAL E MÉTODOS}

Para a produção dos painéis utilizados neste trabalho, foram empregadas partículas de madeira de Eucalyptus grandis provenientes da empresa Satipel, localizada no município de Taquari, RS, e casca de arroz, obtida em uma Indústria de Beneficiamento de Arroz da cidade de São João do Polêsine, RS.

Todo o material (casca de arroz e partículas de madeira) foi acondicionado em sacolas plásticas, devidamente identificadas, e, em seguida, conduzido ao Laboratório de Produtos Florestais (LPF) da UFSM para posterior confecção dos painéis.

Como material ligante, foi usado o polietileno de alta densidade (PEAD) virgem, na forma inicial de grânulos, com densidade de $0,96 \mathrm{~g} / \mathrm{cm}^{3}$. Nenhum agente de acoplamento foi utilizado. Inicialmente, pretendia-se empregar PEAD reciclável, visando à reutilização de embalagens (sacolas) plásticas. A dificuldade na obtenção de informações precisas sobre a composição exata desse material bem como a adição de corantes e a impressão tornaram difícil a experimentação. No entanto, foi possível, em ensaios preliminares, a confecção de chapas de maneira similar às feitas com PEAD virgem.

Os grânulos de PEAD foram dispostos sobre um molde com dimensões previamente calculadas para não alterar a massa específica do material, e transformados em lâminas, as quais facilitaram na montagem dos painéis. Essas lâminas foram cortadas com dimensões de aproximadamente $5 \times 25 \times 0,1 \mathrm{~cm}$, medidas com paquímetro digital e pesadas em balança analítica para determinar a massa específica de cada uma.

A matéria-prima (casca de arroz, partículas de madeira) usada foi acondicionada em câmara climatizada com temperatura constante de $20^{\circ} \mathrm{C}$ e umidade relativa de $65 \%$. Após condicionada, foram retiradas amostras da casca de arroz e das partículas de madeira para determinação do teor de umidade.

Tais amostras foram pesadas, para a obtenção do peso úmido, sendo posteriormente colocadas em estufa a $103^{\circ} \mathrm{C}$ até peso constante, para obter o peso seco e, assim, determinar o teor de umidade. Para as cascas de arroz, o teor de umidade foi de 14,4\%; e para as partículas de madeira, de 12,7\%.

A casca de arroz apresentou uma massa específica aparente a granel de $0,11 \mathrm{~g} / \mathrm{cm}^{3}$, as partículas de madeira, de $0,17 \mathrm{~g} / \mathrm{cm}^{3}$. O tamanho médio da casca de arroz foi de $9 \mathrm{~mm}$ de comprimento, enquanto que as partículas de madeira apresentavam valores em torno de $4 \mathrm{~mm}$. 
Antes de iniciar a manufatura dos painéis, a matéria-prima armazenada foi colocada em estufa a $60^{\circ} \mathrm{C}$, por um período de 24 horas, para alcançar um teor de umidade de aproximadamente $3 \%$.

Os painéis foram montados manualmente em um molde de aço, sem fundo e com tampa, de dimensões $0,5 \times 5 \times 25,5 \mathrm{~cm}$.

O painel foi montado em forma de camadas de acordo com o peso de partículas e o número de lâminas, sendo que o peso das partículas foi cuidadosamente dividido e homogeneizado de acordo com o número de lâminas de PEAD usado em cada tratamento.

Após a montagem, o painel foi levado à prensa quente hidráulica, de laboratório. O período de prensagem foi de 10 minutos, com temperatura dos pratos ajustada em $220^{\circ} \mathrm{C}$. Foram testasdas temperaturas menores; porém, os resultados não foram satisfatórios. Após a prensagem na prensa quente, os moldes permaneceram prensados em uma prensa manual até esfriarem, para que não ocorresse deslocamento do painel e para facilitar a sua remoção do molde. Depois de retirados, os painéis foram identificados e acondicionados em câmara climatizada.

Depois de climatizados, os painéis foram novamente medidos com o auxílio de um paquímetro digital e pesados em balança analítica, para determinação da massa específica de cada painel. Posteriormente, foram confeccionados os corpos-de-prova de acordo com as normas para cada teste. Em seguida à sua confecção, os corpos-de-prova foram novamente armazenados em câmara climatizada até atingir peso constante, para a realização dos testes.

Os testes realizados para avaliação da qualidade dos painéis foram: flexão estática (tensão no limite proporcional e módulo de elasticidade); tração perpendicular à superfície (ligação interna); absorção d'água; inchamento em espessura e inchamento em espessura após 15 ciclos de submersão. Os ciclos consistiram de 20 horas de imersão, seguidas de secagem em estufa a $65^{\circ} \mathrm{C}$ por 4 horas. Ao final dos 15 ciclos os corpos-deprova foram secos em estufa a $103^{\circ} \mathrm{C}$ até peso constante para determinar o teor de umidade e a absorção em cada ciclo.

Os testes seguiram as recomendações da norma norte-americana ASTM D1037 (1995).

A Tabela 1 mostra as combinações empregadas para a confecção dos compósitos com variação na proporção de mistura (partículas de madeira e casca de arroz) e na porcentagem do PEAD usado. Decidiu-se pelo uso de quatro repetições para cada fator, totalizando 64 painéis.

TABELA 1: Relação dos tratamentos utilizados no presente estudo.

TABLE 1: Treatments utilized in the present study.

\begin{tabular}{c|c|c|c|c}
\hline \multirow{2}{*}{ Tratamento } & Número de lâminas de & \multicolumn{2}{|c|}{ Proporção de matéria-prima } & \multirow{2}{*}{$\begin{array}{c}\text { PEAD } \\
\text { (\%) }\end{array}$} \\
\cline { 3 - 4 } & PEAD & Arroz (\%) & Madeira (\%) & 60 \\
1 & 4 & 100 & 0 & 60 \\
2 & 4 & 75 & 25 & 60 \\
3 & 4 & 50 & 50 & 60 \\
4 & 4 & 25 & 75 & 60 \\
5 & 4 & 0 & 100 & 75 \\
6 & 5 & 100 & 0 & 75 \\
7 & 5 & 75 & 25 & 75 \\
8 & 5 & 50 & 50 & 75 \\
9 & 5 & 25 & 75 & 75 \\
10 & 5 & 0 & 100 & 90 \\
11 & 6 & 100 & 0 & 90 \\
12 & 6 & 75 & 25 & 90 \\
13 & 6 & 50 & 50 & 90 \\
14 & 6 & 25 & 75 & 90 \\
15 & 6 & 0 & 100 & 100 \\
16 & 6 & 0 & 0 & \\
\hline
\end{tabular}




\section{RESULTADOS E DISCUSSÃO}

\section{Massa específica}

A massa específica aparente dos compósitos variou entre 0,89 e $0,98 \mathrm{~g} / \mathrm{cm}^{3}$, sendo que o valor esperado era de 0,95 a $1,0 \mathrm{~g} / \mathrm{cm}^{3}$. A dificuldade de controlar a perda de material durante a prensagem e a possível liberação de tensões de prensagem, que poderia variar em função do tipo de partícula, podem ser as causas dessa maior variação da massa específica. Hillig (2000) e Dacosta (2004) em seus estudos, atribuíram a variação na massa específica entre e dentro de chapas aglomeradas às condições de manufatura em laboratório, por causa de uma falta de homogeneidade na distribuição manual para a formação da chapa, ou ainda a diferença na massa específica entre partículas de mesma madeira.

\section{Flexão estática}

A norma de comercialização ANSI A 208.1 das chapas de partículas de alta densidade (entre 0,8 a $1,12 \mathrm{~g} / \mathrm{cm}^{3}$ ) admite para o MOE valores mínimos entre 2,42 e 2,75 GPa. Os valores do módulo de elasticidade (MOE) no presente trabalho oscilaram entre 0,94 e 1,97 GPa (Figura 1). Em comparação com a norma, não houve nenhum valor médio que atingisse o valor mínimo requerido. Cabe ressaltar que a comparação é feita entre uma matriz termofixa (uréia-formaldeído) e uma outra termoplástica (PEAD).

Teixeira et al. (2002), analisando compósitos com polietileno de baixa densidade (PEBD), obtiveram resultados para o MOE que variaram de 1,52 a 1,75 GPa.

O valor do MOE obtido no tratamento com 100\% de PEAD está dentro dos limites apresentados por Doak (1986), que determinou as propriedades mecânicas do PEAD.

Observa-se que, à medida que a porcentagem de casca de arroz na mistura diminui, aumentam os valores para o módulo de elasticidade (MOE), independente da porcentagem de PEAD usada. Porém, esses valores parecem ser maiores quando a porcentagem de 75\% de PEAD é utilizada.

A tensão no limite proporcional $\left(\sigma_{\mathrm{LP}}\right)$ é usada na determinação de cargas de segurança em cálculos estruturais (Teixeira et al., 2002). Também pode ser usada como forma de comparação das propriedades de diferentes materiais. Os valores médios obtidos para $\sigma_{\mathrm{LP}}$ variaram de 12,64 a 24,26 MPa, bem superiores aos encontrados por Teixeira et al. (2002), analisando compósitos de PEBD, que ficaram entre 4,34 e 4,37 MPa. Os valores de $\sigma_{\mathrm{LP}}$ tendem a se tornar maiores à medida em que se aumenta a porcentagem de arroz e diminuem os percentuais de PEAD na mistura. No entanto, fica evidente que todas as combinações estudadas apresentaram valores das propriedades de flexão estática maiores do que aqueles que usaram somente o PEAD na fabricação do compósito.

Até o momento de medição dos valores de deslocamento, não ocorreu ruptura dos compósitos. Por esse motivo, não foi possível calcular o módulo de ruptura (MOR).

Na análise do MOE, em função das variáveis de produção, o melhor modelo para explicar o seu comportamento inclui a massa específica dos compósitos produzidos com partículas de madeira. Como observado na Figura 1, as partículas de madeira causaram um acréscimo no MOE à medida que a sua porcentagem na mistura aumentou. 


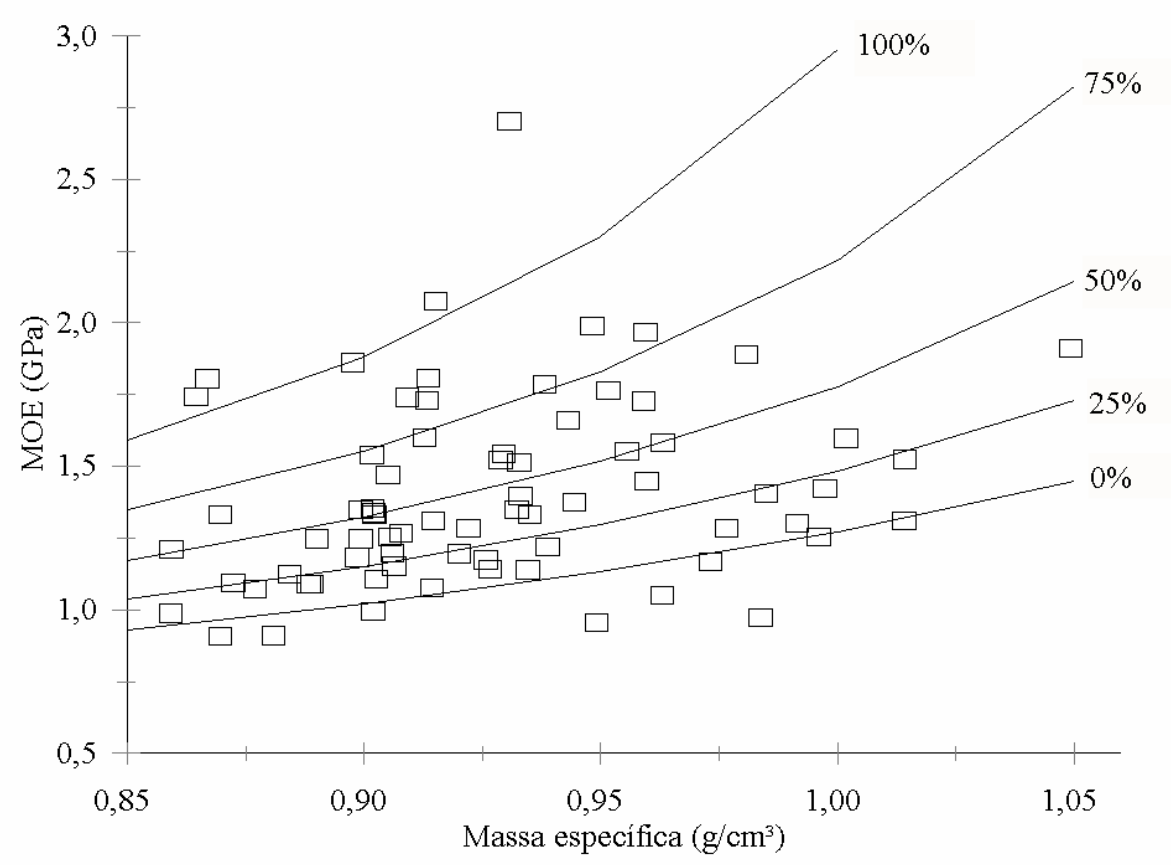

FIGURA 1: Valores do módulo de elasticidade (MOE), observados e ajustados em função da massa específica e da porcentagem de partículas de madeira no compósito.

FIGURE 1: Values of modulus of elasticity (MOE), observed and fitted concerning density and proportion of wood particles content.

O melhor modelo de regressão linear para a $\sigma_{\mathrm{LP}}$ inclui a porcentagem de casca de arroz, a proporção de PEAD e a massa específica (Tabela 2).

TABELA 2: Modelos de regressão ajustados para as propriedades mecânicas dos compósitos em função das variáveis de fabricação.

TABLE 2: Regression models adjusted for the mechanical properties of the composites concerning fabrication parameters.

\begin{tabular}{c|c|c|c|c}
\hline Equação ajustada & $\mathrm{F}$ & Syx & $\mathrm{R}^{2}$ aj. $(\%)$ & $\mathrm{DW}$ \\
\hline $\mathrm{MOE}=1 /\left(2,62057-0,00448587 \mathrm{pm}+0,000035 \mathrm{pm}^{2}-0,00478587 \mathrm{me}\right)$ & 19,81 & 0,1224 & 42,29 & 1,6858 \\
$\sigma_{\mathrm{LP}}=1 /(0,159032-0,000126627$ ca $+0,000407301 \mathrm{PEAD}-0,142096 \mathrm{me})$ & 13,44 & 0,0012 & 32,65 & 1,8707 \\
\hline
\end{tabular}

Em que: $\mathrm{MOE}=$ módulo de elasticidade $(\mathrm{GPa}) ; \sigma_{\mathrm{LP}}=$ tensão no limite proporcional $(\mathrm{MPa}) ;$ me = massa específica $\left(\mathrm{g} / \mathrm{cm}^{3}\right) ; \mathrm{PEAD}=$ proporção de polietileno de alta densidade; $\mathrm{pm}=$ proporção de partículas de madeira; $\mathrm{ca}$ = proporção de casca de arroz; F = teste de F; Syx = erro-padrão da estimativa; ${ }^{2}$ aj. = coeficiente de determinação ajustado; DW = teste de Durbin-Watson.

A Figura 2 mostra que a $\sigma_{\mathrm{LP}}$ é influenciada pela porcentagem de PEAD existente no compósito, sendo que, com o aumento dos valores de PEAD, a tensão no limite proporcional diminui. 


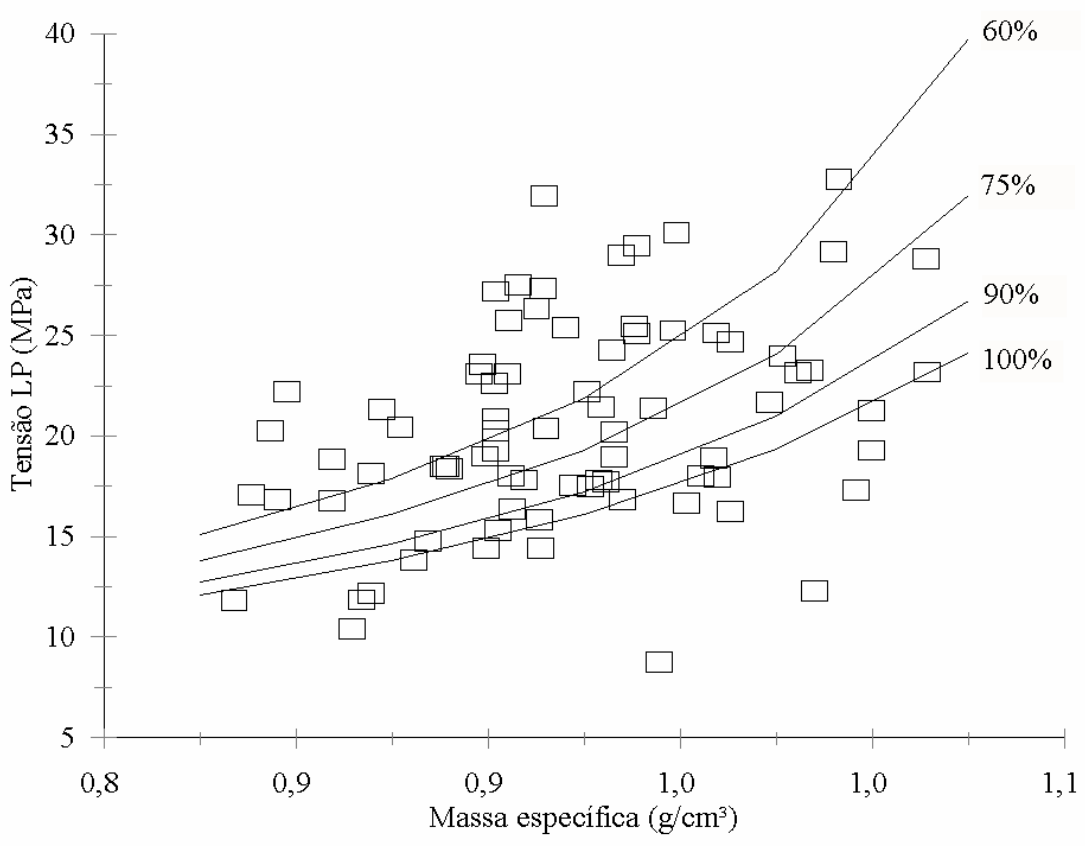

FIGURA 2: Valores de tensão no limite proporcional $\left(\sigma_{\mathrm{LP}}\right)$, observados e estimados em função da massa específica aparente e da proporção de PEAD.

FIGURE 2: Values of tension at proportional limit $\left(\sigma_{\mathrm{LP}}\right)$ observed and estimated concerning density and proportion of HDPE.

\section{Tração perpendicular à superfície da chapa (Ligação interna)}

Os valores médios de resistência à tração perpendicular à superfície (LI) dos compósitos obtidos nos diferentes tratamentos, considerando o efeito do tipo de matéria-prima, a porcentagem de mistura e a porcentagem de PEAD, oscilaram entre 0,24 e 2,8 MPa.

De acordo com a norma ANSI A 208.1, as chapas de partículas de alta densidade (entre 0,8 e 1,12 $\mathrm{g} / \mathrm{cm}^{3}$ ) admitem para LI valores mínimos requeridos entre 0,89 e 0,96 MPa. Dessa maneira, os valores de LI superam os limites recomendados pela norma apenas nos tratamentos em que a proporção de PEAD foi maior ou igual a $90 \%$. Nas demais combinações, independente da participação da casca de arroz e das partículas de madeira, os valores ficaram abaixo desses limites.

Em comparação com a norma DIN 68761(1971), que recomenda um valor mínimo para LI de 0,34 $\mathrm{MPa}$, os valores obtidos no presente trabalho superam os limites exigidos pela norma, com exceção dos tratamentos em que a proporção de PEAD foi de $60 \%$. Nestes, que correspondem aos tratamentos 1, 2, 3, 4 e 5 , os valores ficaram bem abaixo do limite.

O melhor modelo de regressão linear ajustado inclui a porcentagem de PEAD, com um valor de P menor que 0,01 , relacionando significativamente essa variável a um nível de confiança de $99 \%$ (Tabela 3). O coeficiente de determinação sugere que $78,96 \%$ da tração perpendicular à superfície do compósito é explicada pelo modelo matemático.

TABELA 3: Modelo de regressão ajustado para a tração perpendicular dos compósitos em função das variáveis de fabricação.

TABLE 3: Regression model adjusted for internal bond of the composites concerning fabrication variables.

\begin{tabular}{c|c|c|c|c}
\hline Equação ajustada & $\mathrm{F}$ & Syx & $\mathrm{R}^{2}$ aj. (\%) & DW \\
\hline $\operatorname{Ln}(\mathrm{LI})=-5,26429+0,0636636$ PEAD & 455,10 & 0,3313 & 78,96 & 1,5232 \\
\hline
\end{tabular}

Em que: $\mathrm{LI}=$ Ligação interna (MPa); PEAD = polietileno de alta densidade; $\mathrm{F}$ = teste de F; Syx = erro-padrão da estimativa; $\mathrm{R}^{2}$ aj. = coeficiente de determinação ajustado; DW = teste de Durbin-Watson. 
O modelo de regressão para a tração perpendicular à superfície do compósito é mostrado na Figura 3 com os valores ajustados em função da porcentagem de PEAD. Os resultados obtidos nos testes de tração (LI) demonstram que, à medida que se aumenta a quantidade de PEAD no compósito, ocorre um acréscimo na resistência.

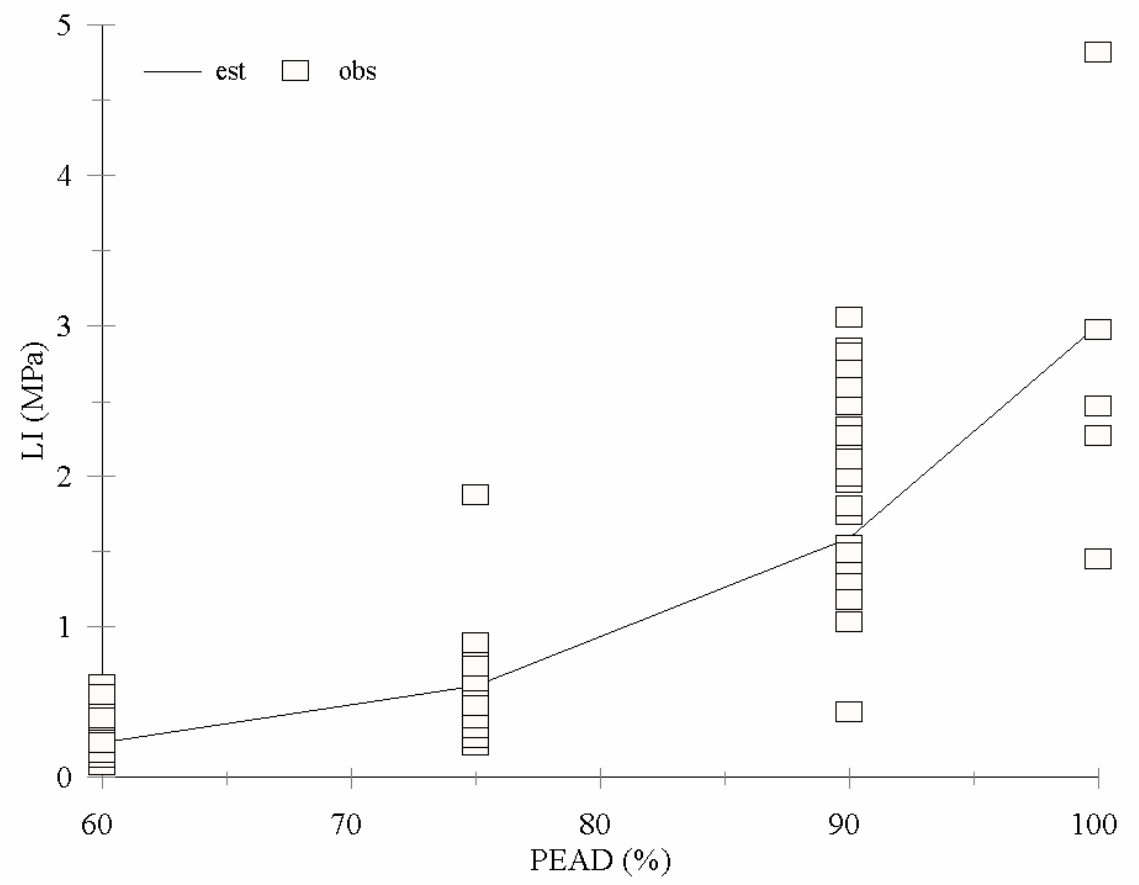

FIGURA 3: Valores de ligação interna (LI), observados e estimados em função da porcentagem de polietileno de alta densidade (PEAD) usada.

FIGURE 3: Values of internal bond (LI), observed and estimated concerning the percentage of PEAD used.

\section{Inchamento em espessura após 2 e 24 horas}

Os valores médios de inchamento em espessura (IE) dentre as combinações estudadas variaram entre 0 e $13,87 \%$.

A proporção de mistura (casca de arroz, partículas de madeira) teve influência direta sobre os valores finais. Quando usaram-se partículas de madeira em maior proporção na mistura, houve um aumento no inchamento em espessura, e um comportamento inverso foi observado em relação à casca de arroz. Constatou-se também que, com o aumento da porcentagem de PEAD, diminuiu o inchamento do compósito em ambos os casos.

Boeglin et al. (1997) obtiveram valores de 1 a 10\% de inchamento em compósitos com 75\% de partículas de madeira. Isso pode ser explicado pela maior proporção de partículas de madeira no composto, o que resulta em uma maior quantidade de sítios disponíveis para a penetração da água no interior do compósito (Teixeira et al., 2002).

Em comparação com as exigências da norma alemã (DIN, 1971) que admite valores até 12\% de inchamento em espessura após 24 horas de imersão, os valores ficaram dentro dos limites estabelecidos, com exceção dos tratamentos 3 e 5 que apresentaram valores muito elevados.

Na análise do IE, em função das variáveis de produção, o melhor modelo encontrado foi IE $24 \mathrm{H}=$ $(13,7227-1,34663 \sqrt{P E A D}-0,00700234 \mathrm{ca})^{2}$, que inclui a proporção de casca de arroz e porcentagem de PEAD. O modelo selecionado apresenta um valor de $\mathrm{F}=310,4$, com um Syx $=0,47219$ e o $\mathrm{R}^{2}$ ajustado $=$ $80,19 \%$.

A Figura 4 mostra o inchamento em espessura após 24 horas de imersão, com valores ajustados em função da porcentagem de PEAD, para as cinco proporções de casca de arroz (0, 25, 50, 75 e 100\%). Pode-se 
verificar que o menor inchamento em espessura após 24 horas foi encontrado nos compósitos produzidos com $100 \%$ de casca de arroz. Os valores diminuíram com o aumento da proporção de PEAD. Quanto menor a participação de partículas de madeira no compósito menor foi o valor do inchamento em espessura. Essa mesma relação entre a porcentagem de partículas de madeira e o inchamento em espessura já havia sido observada por Teixeira et al., 2002.

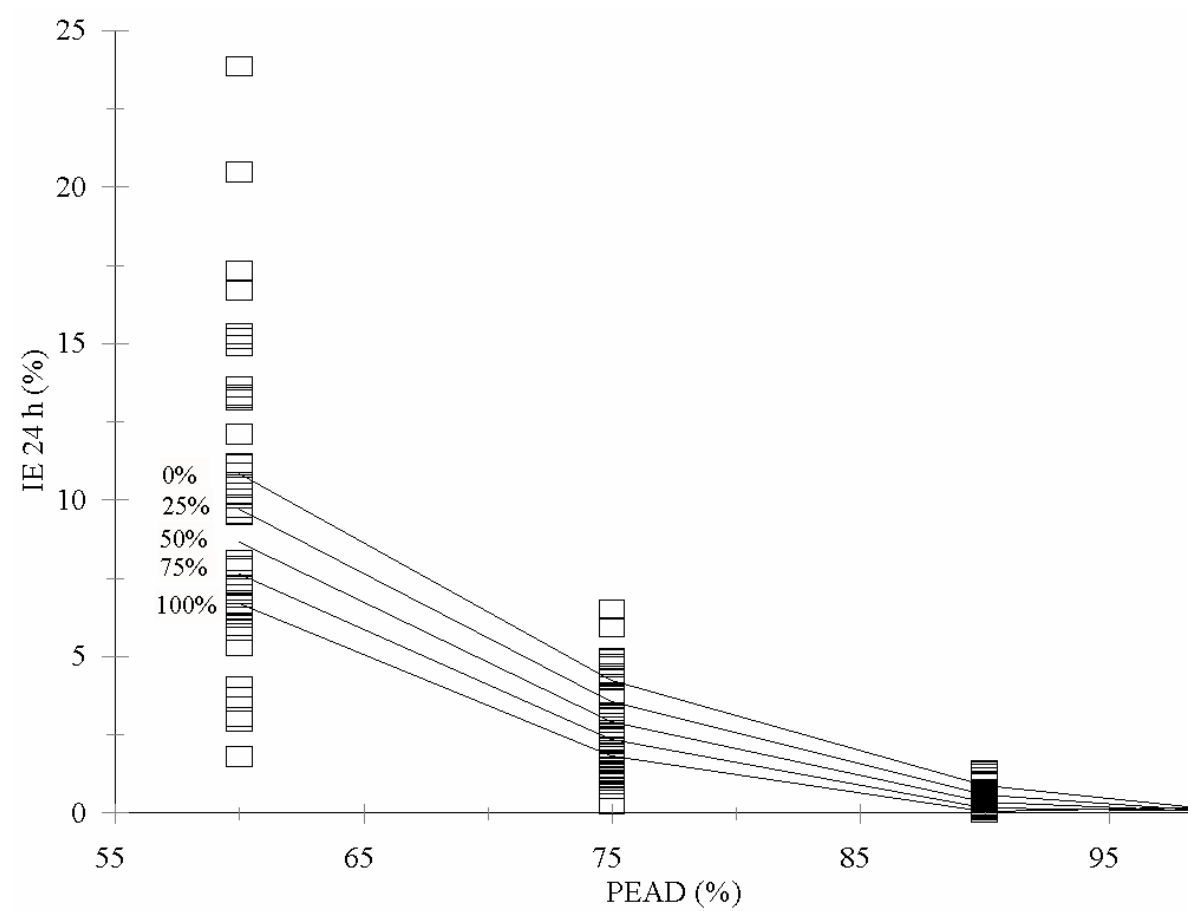

FIGURA 4: Valores de inchamento em espessura 24 horas (IE 24 h), observados e ajustados em função da porcentagem de polietileno de alta densidade (PEAD) e da proporção de casca de arroz.

FIGURE 4: Values of thickness swelling 24 hours (IE 24 h), observed and adjusted concerning HDPE and rice husk proportion.

\section{Absorção d’água}

Os valores médios de absorção d'água, alcançados após um período de 2 e 24 horas de imersão, foram de 0,98 a $24,51 \%$, com exceção do tratamento 16 , no qual não foi observada absorção d'água em razão de o painel ser composto apenas de PEAD. Teixeira et al. (2002), trabalhando com proporções de 40, 50 e $60 \%$ de polietileno de baixa densidade (PEBD), encontraram valores entre 2,77 e 25,50\%. Boeglin et al. (1997) obtiveram resultados em torno de 50\% após 24 horas em compósitos com menor porcentagem de plástico.

Quando comparados com os valores médios de chapas aglomeradas (USDA, 1999), os resultados obtidos no presente trabalho mostram-se dentro dos limites estabelecidos pela norma, tanto para as chapas de média como de alta densidade. Pedrazzi (2005), trabalhando com chapas aglomeradas com variação na porcentagem de adesivo, encontrou valores médios que oscilam entre 41,05 e 81,48\% de absorção d'água.

Os menores valores de absorção d'água foram encontrados para os tratamentos 14, 11, 13, 15 e 12, os quais não chegaram a absorver $2 \%$ de água. Observa-se que esses tratamentos são compostos por uma proporção de PEAD de $90 \%$. Já aqueles tratamentos com 60\% de PEAD apresentaram os maiores valores de absorção d'água. De uma maneira geral, as combinações que apresentam proporção de 60 e $75 \%$ de PEAD, a absorção d'água aumentou com o acréscimo da porcentagem de partículas de madeira.

Na análise de absorção d'água em função das variáveis de produção, o melhor modelo para explicar a absorção em peso d'água após 24 horas, para todos os compósitos fabricados, inclui a porcentagem de PEAD. O modelo escolhido foi:

$$
\operatorname{Ln}(\mathrm{AB} 24 \mathrm{H})=5,40688-0,000666537 \mathrm{PEAD}^{2}
$$


A Figura 5 mostra o gráfico para absorção d'água com os valores ajustados em função da porcentagem de PEAD. Observa-se que os valores da absorção d'água após 24 horas diminuíam com o aumento da porcentagem de PEAD, tornando-se praticamente nulos a $100 \%$. O tipo de matéria-prima mostrou-se pouco influente.

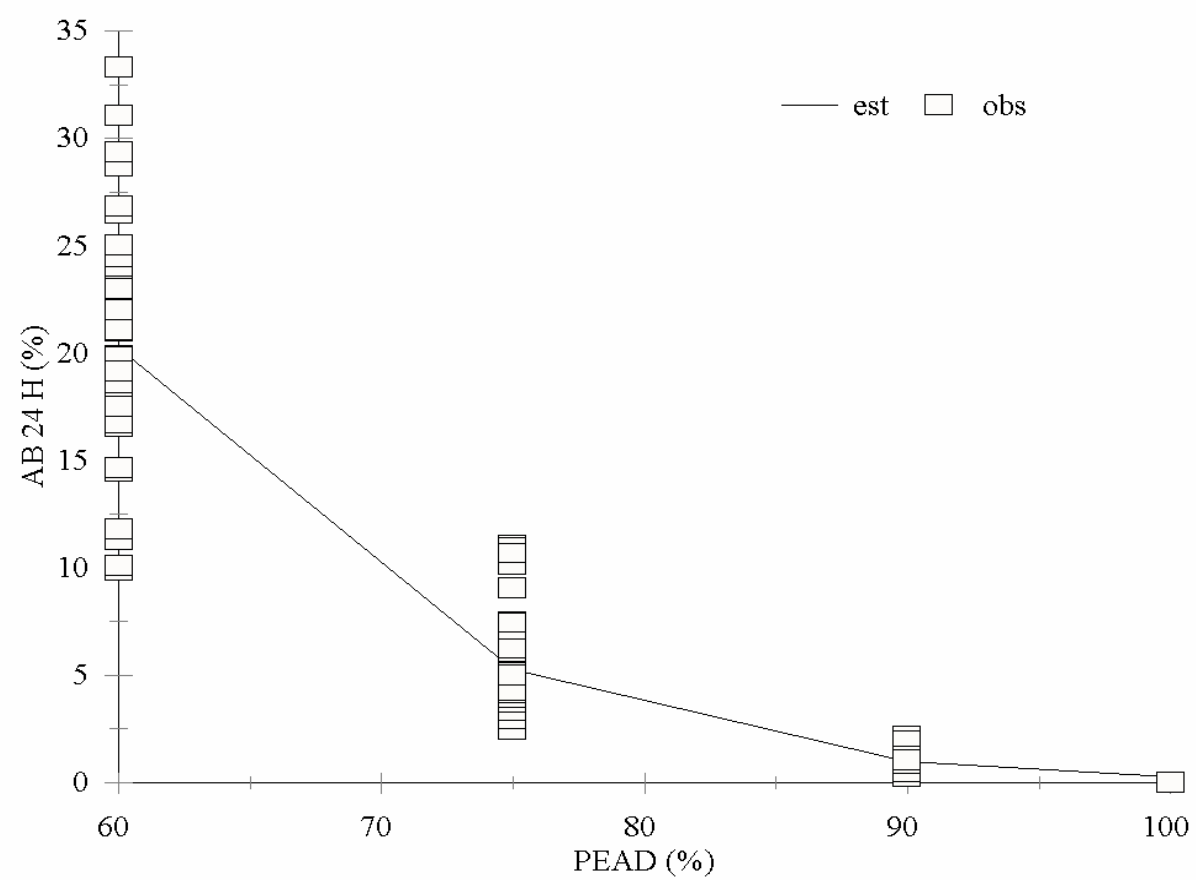

FIGURA 5: Valores de absorção d'água após 24 horas de imersão (AB 24h), observados e estimados em função da porcentagem de polietileno de alta densidade (PEAD).

FIGURE 5: Values of water absorption after 24 hours soaking (AB 24h), observed and estimated concerning HDPE proportion.

\section{Inchamento em espessura após 15 ciclos de submersão}

Conclui-se que, nas combinações que apresentavam uma proporção menor de PEAD, ocorreu uma delaminação maior do que as demais; já em relação ao tipo de matéria-prima usada na confecção do compósito, esta se mostrou pouco influente.

Teixeira et al. (2002) realizaram ensaios com algumas adaptações da norma, deixando os corpos-deprova imersos em água por três semanas, tendo espessura e peso controlados, e duas semanas em estufa a $60^{\circ} \mathrm{C}$. Depois de condicionadas em câmara climatizada, realizaram novas medidas para o cálculo do que chamou de inchamento em espessura não-recuperável, observando que os corpos-de-prova retornaram quase que completamente à espessura normal, sobretudo nos tratamentos com maior proporção de PEBD.

$\mathrm{Na}$ análise do inchamento em espessura após 15 ciclos em função das variáveis de produção, o melhor modelo para explicar o IE 15(\%) para todos os compósitos confeccionados inclui a porcentagem de PEAD e a proporção de casca de arroz na mistura, como mostra a Tabela 4 o coeficiente de determinação indica que $87,65 \%$ do inchamento em espessura é explicado pelo modelo matemático.

TABELA 4: Equação ajustada para o inchamento após 15 ciclos dos compósitos em função das variáveis de fabricação.

TABLE 4: Fitted equation for the thickness swelling after 15 cycles of the water soaking of the composites concerning variables of fabrication.

\begin{tabular}{c|c|c|c|c} 
concerning variables of fabrication. & F & Syx & $\mathrm{R}^{2}$ aj. (\%) & DW \\
\hline Equação ajustada & 462,54 & 0,53113 & 87,65 & 1,8623 \\
\hline $\operatorname{Ln}(\mathrm{IE})=10,1505-0,00454816$ ca $-0,116445$ PEAD &
\end{tabular}

Em que: IE = Inchamento em espessura; $c$ a = proporção de casca de arroz; $\mathrm{PEAD}=$ polietileno de alta densidade; $\mathrm{F}=$ teste de F; Syx = erro-padrão da estimativa; R²aj. = coeficiente de determinação ajustado; DW = teste de DurbinWatson. 
A relação entre a porcentagem de PEAD e o inchamento em espessura após 15 ciclos é mostrada na Figura 6. Observa-se que as curvas apresentam comportamento semelhante àquele evidenciado na Figura 4, em que o aumento na proporção de PEAD na mistura resulta numa diminuição do inchamento em espessura no compósito.

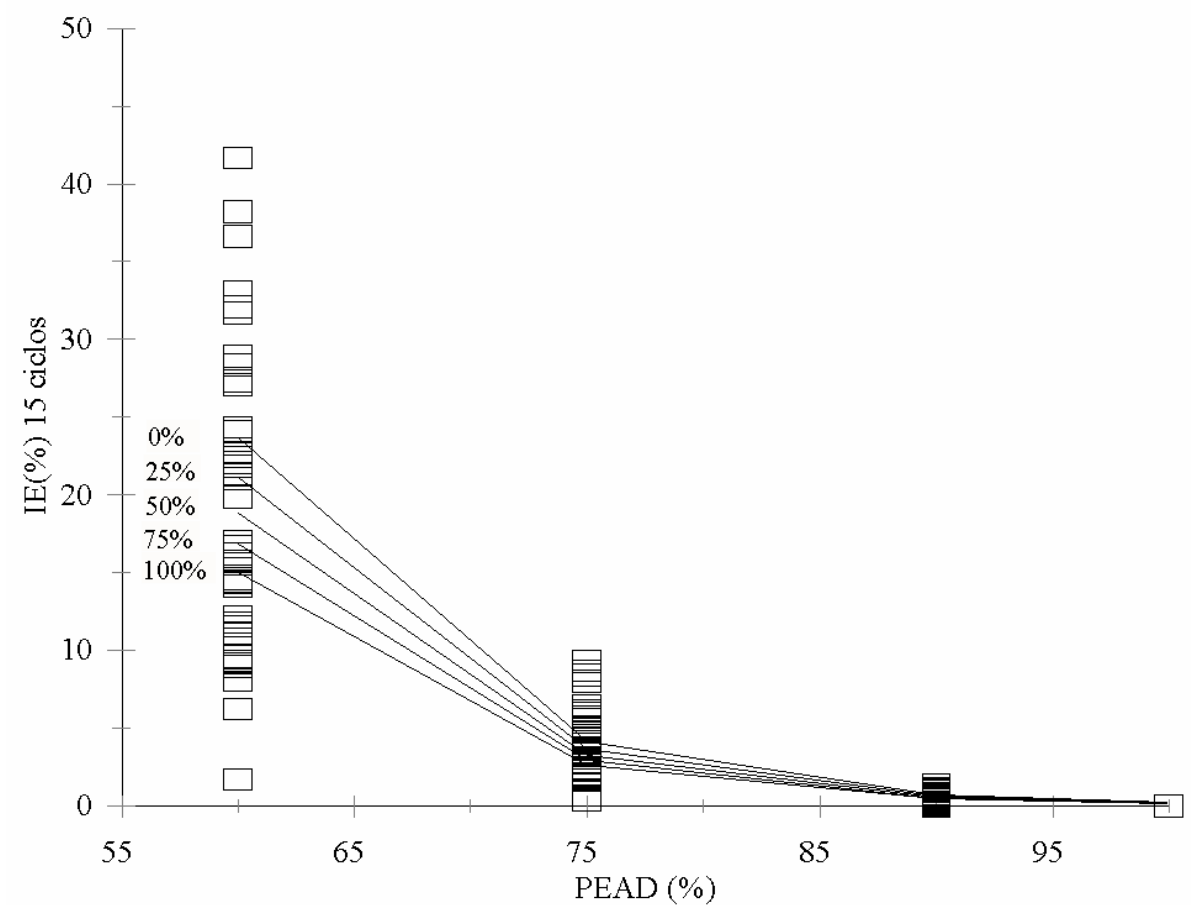

FIGURA 6: Valores de inchamento em espessura após 15 ciclos de imersão (IE 15ciclos), observados e ajustados em função da porcentagem de polietileno de alta densidade (PEAD) e da proporção de casca de arroz.

FIGURE 6: Values of thickness swelling after 15 cycles of water soaking (IE 15 ciclos), observed and adjusted concerning HDPE percentage and rice husk proportions.

\section{CONCLUSÕES}

Com base nos resultados obtidos neste estudo, as seguintes conclusões são apresentadas:

O MOE médio dos compósitos produzidos tanto com casca de arroz como partículas de madeira ficou abaixo dos padrões estabelecidos pelas normas de comercialização de painéis aglomerados produzidos com resina termofixa. No entanto, esses valores estão de acordo aos normalmente observados para materiais termoplásticos.

Dentre as variáveis estudadas, a massa específica do compósito foi a que mais influenciou no módulo de elasticidade, seguida da porcentagem de partículas de madeira.

De maneira geral, tanto o MOE, como a tensão no limite proporcional sofreram influência direta da massa específica.

Os valores médios para ligação interna ficaram dentro dos limites determinados pelos padrões internacionais, mas, nos tratamentos em que se usou proporção de PEAD menor que $75 \%$, os valores obtidos foram inferiores.

O inchamento em espessura foi maior quando a mistura apresentava maior proporção de partículas de madeira, sendo que, à medida que se elevou a porcentagem de PEAD, o inchamento diminuiu independente do tipo de partícula. Os valores de inchamento em espessura ficaram dentro dos padrões internacionais de comercialização, com exceção de duas combinações de teor de PEAD de $60 \%$ e da proporção maior de partícula de madeira no compósito.

Para a absorção d’água, a variável que exerceu maior influência foi a proporção de PEAD, seguida da 
massa específica. Combinações com maior porcentagem de PEAD apresentaram valores mínimos ou, em alguns casos, nulos, de absorção d'água.

Os resultados encontrados para o inchamento em espessura após 15 ciclos de submersão foram semelhantes aos dos testes de IE 24h, e as combinações com menor proporção de PEAD delaminaram mais em relação às demais.

Sugere-se em trabalhos futuros, variar a espessura das lâminas de PEAD sem alterar a sua massa específica, para uma melhor distribuição de matéria-prima entre as camadas e a utilização de um agente de acoplamento, de forma a melhorar a compatibilidade entre as fibras e o PEAD.

De um modo geral, os compósitos produzidos com PEAD, casca de arroz e partículas de madeira puras ou misturadas, apresentaram boa qualidade, evidenciando a viabilidade de uso desses materiais na confecção do compósito, e com isso, oportunizando o aproveitamento de materiais tidos como descarte, em alguns setores da cadeia produtiva.

\section{REFERÊNCIAS BIBLIOGRÁFICAS}

AMERICAN SOCIETY FOR TESTYNG AND MATERIALS. Standard test methods for evaluating properties of wood-base fiber and particle panel materials. ASTM D 1037 - 93, Philadelphia, Pa. 1995.

BOEGLIN. N.; TRIBOULOT. P.; MASSON. D. A feasibility study on boards from wood and plastic waste: bending properties, dimensional stability and reveling of the board. Holz als Roh-und Werkstoff, n. 55, p.13-16. 1997.

BULAKUL, S. Economic and technical aspects of the utilization of cereal stalks for the production of panels. United Nations Industrial Development Organization Document (UNIDO) ID/WG.83/10. United Nations Industrial Development Organization (UNIDO) Expert Working Group meeting on the production of panels from agricultural residues; 1970 December 14-18; Vienna, Austria. 39 p.

BNDES. Polietileno de alta densidade (PEAD). 2000. Disponível em: <http://www.bndes.gov.br/conhecimento/relato/peadx.pdf $>$. Acesso em: 24 mar. 2003.

CASALINA, S. L. Rigid, flexible, and composite solid objects having cellulose-containing rice hull particles and radiation-induced polymer. Patent, P.N.: US 3660223, I.D.: 680410. 1972.

CEPIS. Disponível em < http://www.cepis.org.pe/ >. Acesso em: 12 mar. de 2003.

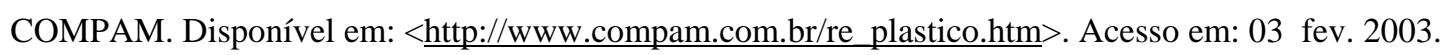

CHEN, T. Y. Studies on the manufacture of particleboard from rice hull. K’o Hsueh Fa Chan Yueh K'na (National Science Council Monthly, ROC). v.7, n.1, p.32-45, 1979.

DATAMARK. Os números do mercado de embalagens. 2002. Disponível em: < $\underline{w w w . d a t a m a r k . c o m . b r /-~}$ newdatamark/> Acesso em: 20 maio 2003.

DACOSTA, L. P. E. Utilização de resíduos do processamento mecânico da madeira para a fabricação de chapas aglomeradas. 2004. 118f. Dissertação (Mestrado em Engenharia Florestal) Universidade Federal de Santa Maria, Santa Maria, 2004.

DIN. GERMAN STANDARDS COMMITTEE: Deutschen Normanausschuss. Specifications for particleboard. DIN 68761(1) - 1961 (3). Holz, 1971.

DOAK, K. W. Ethylene Polymers. In: MARK, H. M.; BIKALES, N. M.; OVERBERG, C. G.; MENGES, G. Encyclopedia of Polymer Science and Engineering. New York : John-Wiley \& Sons, 1986. v. 6

ENGLISH, B.; CLEMONS, C. M.; SARK, N.; SCHNEIDER, J. P. Waste-wood-derived fillers for plastics. Madison : U.S. Department of Agriculture. Forest Service, Forest Products Laboratory, 1996. 15p. (Gen. Tech. Rep. FPL-GTR91)

HANCOCK, W. V.; CHANDRAMOULI, P. Comparative properties of rice-husk board, particle board, and wafer board. Journal of the Indian Academy of Wood Science, v.5, n.1, p.18-27, 1974.

HILLIG, E. Qualidade de chapas aglomeradas estruturais, fabricadas com madeiras de Pinus, Eucalipto e Acácia negra, puras ou misturadas, coladas com tanino-formaldeido. 2000. 96f. Dissertação (Mestrado em Engenharia Florestal) - Universidade Federal de Santa Maria, Santa Maria, 2000.

IRGA. Informativo IRGA. 1996. Disponível em: <http://irga.rs.gov.br>. Acesso em: 07 set. 2001.

JOHN, V. M. Pesquisa e desenvolvimento de mercado para resíduos. In: WORKSHOP RECICLAGEM E 
REUTILIZAÇÃO DE RESÍDUOS COMO MATERIAIS DE CONSTRUÇÃO CIVIL, São Paulo, 1996. Anais . São Paulo : Antac, 1996. p.21-30.

KAEFER, L. F; Concreto de Alto Desempenho com Sílica de Casca de Arroz. Disponível em: < http://www.unilivre.org.br >. Acesso em: 15 ago.2002.

MACIEL, A. da S. Chapas de partículas aglomeradas de madeira de Pinus elliottii ou Eucalyptus grandis, em mistura com poliestireno e polietileno tereftalato. 2001. 115f. Tese (Doutorado em Ciências Florestais) Universidade Federal de Viçosa, Viçosa, 2001.

MONTENeGRO, R.S.P.; ZAPORSKI, J.; RIBEIRO, M.C.M. Polietileno de alta densidade. Disponível em: $<$ www.bnds.gov.br/conhecimento/relato/peadx.pdf $>$. Acesso em: 15 ago. 2002.

MORAES, et. al. Não se pode esconder o lixo debaixo do tapete: resíduos sólidos - problemas e soluções. Belo Horizonte: [s.n], 1994.

PEDRAZZI, C. Qualidade de chapas de partículas de madeira aglomeradas com resíduos de uma indústria de celulose. 2005. 122f. Dissertação (Mestrado em Engenharia Florestal) - Universidade Federal de Santa Maria, Santa Maria, 2005.

RICEBOARD. Technology offter. Disponível em: <http://www.nrdcindia.com/>. Acesso em: 03 ago.2001.

TEIXEIRA, D.E.; MOREIRA, J.M.A.P.; COSTA, A.F.da. Confecção de composto de madeira-plástico utilizando resíduos de Eucalyptus grandis Hill Ex Maiden e polietileno de baixa densidade (PEBD). Rev. Floresta e Ambiente, v.9, n.1, p.72-80, 2002.

UNITED STATES DEPARTMENT OF AGRICULTURE. Wood handbook: wood as an engineering material. Washington : USDA, 1999. (Agriculture Handbook ; 72)

VASISHTH, R. C. Water resistant composite board from rice husk. In: UNIDO/FAO/ECAFE INTERREGIONAL SEMINAR ON INDUSTRIAL PROCESSING OF RICE, 1971, Madras. Proceedings... Vienna : United Nations Industrial Development Organization, 1971. 9 p. (United Nations Industrial Development Organization Document (UNIDO) ID/WG/89/23) 